\title{
15
}

\section{PRME NORDIC CHAPTER}

\section{Guénola Abord-Hugon Nonet, Caroline Aggestam Pontoppidan, Caroline Dale Ditlev-Simonsen, Jan Hermes, Leena Lankoski, Sofia Lundberg, Sanchi Maheshwari, Maria Perrotta Berlin, Samuel Petro Sebhatu, Nikodemus Solitander and Mattias Sundemo}

\subsection{Introduction}

One could say that the concept of Sustainable Development was, if not invented, then at least popularized in the Nordics by Gro Harlem Brundtland. Brundtland's 1987 UN-Report "Our Common Future" argued that Sustainable Development had to incorporate social, environmental and economic components and has been a very important and powerful narrative throughout the world ever since. In the Nordics this understanding of sustainability has permeated the educational systems from preschool all the way into higher education and academic research. The Brundtland understanding of sustainability has been (at least before the popularization of the UN Sustainable Development Goals, SDGs) a central starting point for the discussion on sustainability in most contexts. An important aspect of the PRME Nordic Chapter has been a shared notion of the importance of self-reflexivity (c.f. Cunliffe, 2009) regarding the role of higher education, and particularly the role of Business and Economics education, where the 
response to pressing sustainability challenges has arguably been slow (c.f. Rasche and Gilbert, 2015; Roscoe, 2020).

Even though there are important similarities within the Nordic countries (welfare states with universal access to healthcare and free education, for example) emphasis on sustainability differs between schools. Some schools emphasize "responsible management" based on strong research environments in related disciplines whereas other schools with strong research environments in other disciplines emphasize "sustainability" in more general terms. This somewhat different language simply acknowledges the diverse nature and the notion of both "responsible management" and "sustainability." The introduction of the SDGs has somewhat shifted the focus from a more conceptual discussion to one more focused on delivering impact.

In this chapter, we first describe the creation of the PRME Nordic Chapter in its socioeconomic and sociocultural context, elaborate on the role the Chapter plays in higher business education, introduce theoretical and empirical angles to Nordic responsible management education and conclude with a critical reflexive view on the Chapter and its future.

\subsection{The creation and pluralistic context(s) of the PRME Nordic Chapter}

The foundations for the successful formal establishment of the PRME Nordic Chapter in 2014 can be understood in the context of some of the values and norms shared across the Nordic region, including shared notions of responsibility and sustainability, and in the long relational histories between the individual schools. Within the Nordics, cooperation is often seen positively and building of trust between stakeholders is highly valued (c.f. Strand et al., 2015), which is mirrored in the PRME Nordic Chapter. The Chapter is deeply embedded in some common social, cultural, and socioeconomic backgrounds and histories.

While the Nordic societies are not homogeneous, they can be characterized, in broad terms, by a strong role of the state and consequential regulation of everyday life, by a high level of trust between people and toward social systems, and by seeking consensus in decision-making, which includes an emphasis on equality/egality and is reflected in e.g., comparatively homogeneous income 
distribution, tax-funded free education, but also reduced incentives for competition. The post-WWII time is characterized by Nordic governments offering public services such as health care, elderly care, and education, as part of leading and governing economic, social, and environmental responsibility. In the private sector, responsibility has historically been manifested through abiding to given social norms and regulations, including the provision of jobs and the payment of taxes. Sustainability and responsibility remained firmly in the domains of the political without strong involvement of firms (De Geer et al., 2009), thus also remaining present but not very explicit in the business school curriculum. Even though the last decades have witnessed a change in this allocation of responsibilities, by which companies are becoming increasingly conscious of their responsibility toward society, the characteristics of regulation, trust and consensus have had a strong impact on the requirements for management education in Nordic HEIs. The PRME Nordic Chapter is thus best understood in these historical legacies of trust and consensus, while situated in an environment where business and business schools are expected to both increasingly adopt and shape responsibility and sustainability.

Equally important as understanding the foundations for success and collaboration, however, is to understand that relational spaces for coming together in person to openly share, discuss and debate common responsible management education (RME) histories and challenges often only need the lightest mediation. The PRME Nordic Chapter has always been active in seeking and carving out such spaces. Arguably, the PRME Secretariat has from the beginning understood its boundary spanning role (Hodge et al., 2011) in cultivating a dynamic relationship between situated science/academia and the global principles as essential for responding to the complex social challenges of Responsible Management Education (RME) particularly through cultivating and supporting such relational spaces.

Similarly, PRME Nordic Chapter has since its conception understood the value of PRME Secretariat to provide, at least in the initial phase, contextual spaces for collaboration, and recognized the institutional and personal support the Secretariat provides to bring the schools together - such as the foundational role of the PRME Manager for Regional Chapters, as well as the various relational spaces provided for both formal and informal meetings.

Arguably two of such relational spaces proved foundational to the successful establishment of collaboration and trust of the Chapter:

The first was the "Sustainability in a Scandinavian Context" conference hosted by Copenhagen Business School in June 2013. Fitting to the 
outcome, the very theme of the conference was the assumption that there is something in common or even unique among Nordic organizations in how they approach sustainability, perhaps giving the initial participating schools scientific legitimacy to something they already knew - that trust and pragmatic cooperation are highly valued and needed in order to create meaning through a common "serious reading" (Solitander et al., 2012) of the Principles for Responsible Management Education.

The second foundational relational space was the PRME Summit in Bled, Slovenia, in September 2013. Here, outside of the formality that often comes with academic conferences, representatives of eight Nordic schools (Copenhagen Business School, Denmark; Aarhus University, Denmark; Lund University School of Economics and Management, Sweden; Háskólinn í Reykjavík, Iceland; the School of Business and Service Management, Finland; Turku School of Economics, Finland; Hanken School of Economics, Finland; Aalto University, School of Business, Finland) came together in an informal setting to hammer out a very Nordic consensus-driven view on PRME and the potential role and aim of a regional chapter. There is a physical artifact from this meeting that sums up a seemingly axiomatic yet somehow, in the world of business schools, almost contrarian view on the foundations of a regional Chapter, when scribbled on a napkin are the words "a non-dinner-speech approach to PRME". This slogan, while informal, has always implicitly guided the PRME Nordic Chapter's activities.

Such an emphasis on action and impact can also be contextualized in the emergence of a larger debate about sustainability and education that was ongoing on a global scale. Temporally the establishment of PRME Nordic Chapter coincided with a larger debate about both the changing role of business schools (through the notion of RME), and the larger question about education for sustainable development, highlighted not least through the development of the UN SDGs. Education for sustainable development (ESD) in higher education is intended to encourage individuals to become active participants in building more sustainable societies and achieving the SDGs. It is supposed to empower engagement in real and relevant social problems (Barrineau et al., 2019). Thus, within PRME Nordic Chapter the emphasis since establishment has been to jointly explore how to achieve impact through education and research.

A shift from loose to tight framing may involve changes to the curriculum, management, leadership and governance throughout an organization or network. Thus, there was recognition that PRME Nordic Chapter itself 
is an actor in the development of society in a tight framing of sustainability - putting further emphasis on the question how to organize. The development of the MoU also revealed another characteristic of Nordic values and ways of organizing, when the schools showed hesitancy to recreate a more hierarchical governance system that was present in some of the previously established regional Chapters, instead trusting that the production of consensus is possible and even desirable without steep hierarchies. Yet there was recognition that a shift toward a tight framing of sustainability could not simply rely on informal cooperation. The bottom-up implementation of ESD needs to be complemented by more top-down implementation (Holmberg et al., 2012). ${ }^{1}$ The formality of the MoU and the formal governance hierarchies within it serves to provide reliable ways to progress toward predefined goals of ESD (ibid).

The first MoU was finalized just two months after the meeting in Bled and signed by Nordic schools representing all Nordic countries, Norway, Island, Sweden, Finland, and Denmark. Copenhagen School of Business was elected in a consensus vote as the first official chairing school for the chapter for the period 2014-2016. The Chapter was officially established on September 13, 2014 with Hanken taking over the chapter chair mid-cycle in October 2014.

\subsection{Role of the PRME Nordic Chapter in higher business education}

One first basic role for the Chapter is to provide a space for the dissemination of ideas and best practices between participating schools through meetings and workshops. There are several examples of such best practices that are developed at individual schools but can be communicated to the other Chapter schools. For example, at Aalto University all the courses have been mapped against the SDGs by the responsible teachers, and this information has been brought to the course descriptions so that students can more easily find courses that deal with particular sustainability themes. Our Chapter members decided in 2020 to increase opportunities for sharing and learning from each other. 2020 saw the beginning of our Chapter quarterly online "breakfasts" where members join at their own will and share, learn and contribute to collaborative projects. This book chapter is a direct outcome of our 2020 collaborative meetings.

Finally, the Chapter also contributes to PRME and the advancement of responsible management education beyond its regional borders. PRME 
Nordic Chapter has always participated in PRME Global meetings, and several Nordic members have played essential roles as champions or advanced members by means of their critical perspective and steering progress.

\subsection{Empirical perspectives on responsible management education - what does the PRME Nordic Chapter achieve collaboratively?}

In this section some collaborative projects that have or are managed collaboratively by different Nordic PRME members are introduced.

The Chapter serves as a platform to facilitate collaborations around larger projects. One of the first concrete large-scale projects where the schools identified the possibility to cooperate and where it was clear that it was easy to prove value for both individual schools and the Chapter itself was the creation of a joint $\mathrm{PhD}$ course with three modules between three different Nordic PRME school locations. This joint PhD course draws from the particular profiles of different schools, gathers a critical mass of both teaching resources and students, and enables interaction and the creation of networks across the region. The course is comprised of three modules between three different Nordic PRME school locations. Students can apply from all PRME schools in the region and, if there is availability, also from other schools. The first implementation of the course was launched by Stockholm School of Economic, BI Norwegian Business School and Hanken School of Economics in 2016, and a second round was organized by Aalto University, Stockholm University and Copenhagen Business School in 2018-2019. A potential third round is currently being discussed by the different schools with the perspective of collaborative funds application to help support this initiative.

\subsubsection{Common carbon literacy training \& research conference}

UN PRME 2019 Research Conference was hosted by Jönköping International Business School. This was a unique opportunity for Nordic members to network further and create further collaboration. During the conference, several Nordic members took the Carbon Literacy Training codesigned by Nottingham Business School and Copenhagen Business School.

Through the PRME Working Group on Climate Change and Environment, Nordic PRME representatives have been trained to carry out our Carbon 
Literacy Training. A few schools including Copenhagen Business School and Jönköping International Business School are now working on adapting the training to their local context. It can be expected to see the emergence of a Nordic Carbon Literacy training in the near future.

\subsubsection{Further engaging students in transforming Nordic schools}

All PRME Nordic schools have witnessed and supported the rise of students' associations and initiatives, created with the purpose of transforming their campus for Agenda 2030. Several student organizations exist, and it is our purpose to help connect them so that they can amplify the work that is developed for the SDGs.

Efforts have been slowed down by COVID-19 lockdowns, but it is our ambition to encourage further students' collaboration across Nordic countries (e.g., Oikos Helsinki [Hanken Finland], Students for Sustainable Action [Jönköping International Business School], Oikos Copenhagen [CBS], SSE Students for Climate Action, Handels Students for Sustainability [Gothenburg]).

A Student Ambassadors Exchange program was proposed to let engaged students across the different schools share their experiences and raise engagement in other schools. This was initiated by Stockholm School of Economics and the students have already reached out to a few schools despite limitations created by the COVID-19 context.

\subsubsection{Collaborative effort to map the Nordic Chapter's online education resources}

Across Nordic PRME members a focus has been on advancing sustainability education through the use of digitalization. The digitalization evolution is turning distance learning into various forms of E-learning ${ }^{2}$. Education for sustainability and for a sustainable society has across the Nordic PRME members been supported by E-learning strategies, more explicitly. E-learning has been proposed to enable, contribute to, as well as play a role in, the transition to sustainable societal patterns (Azeiteiro et al., 2015). This has made the E-learning and digitalization angle of education for sustainable development particularly relevant for PRME scholars engaged in sustainability in higher education, across the Nordics. The collaborations and conversations across the Nordic PRME schools foster traditions to advance education for sustainability. 
Table $15.1^{3}$ illustrates more examples of pure E-learning and blended learning mechanisms that have emerged across the Nordic PRME schools.

Within the development of mandatory online E-learning for formal education to advance education in sustainability, the options are still limited.

\subsubsection{Chapter sharing sessions about strategies, tools and ideas to help facilitate a sustainability transition}

The Nordic Chapter is creating spaces for sharing about the progresses made at the different schools. The goal is to help inspire our partners, answer their questions and help them adopt some of the innovative processes for RME that were initiated at a first mover school. Time is allocated to sharing practices during the Nordic annual meeting and also during our quarterly meetings.

As a result of these spaces allocated to sharing inspiring practices, a few inspiring examples of work related to responsible management education in education, research, governance, and strategy are listed here:

- A university-wide effort toward advancing the connection between curriculum and responsibility, ethics and sustainability (RES) was initiated a decade ago by Professor Kai Hockerts. As of 2020, CBS PRME is working toward building on the foundations of RES in curricula to include linking the analysis of degree programs to three useful initiatives, or pillars, of RME.

- At Umeå Sschool of Business, Economics and Statistics (USBE) the connection between the 17 SDGs and the Brundtland definition of sustainble development and curriculum follows an imbeded model and is certified according to ISO14001. Systematically, local learning goals on sustainability and ethics have been incorporated into curricula. In the spirit of the Nordic culture, courses are designed to encourage students to take on responsibility and an active role in the learning process, stimulate the students' curiosity and capacity for innovation, and allow for reflection and a critical approach to global challenges.

- The case of Karlstad Business School (KBS) fits well with the Nordic culture of transparent self-assessment and self-criticism. The school was looking into transformative change by implementing the SDGs to develop its curriculum based on sustainability and business societal practices. The ambition is also to integrate the distinctive ongoing studies/research and dialogues with the stakeholders within the curriculum for responsible management education. 


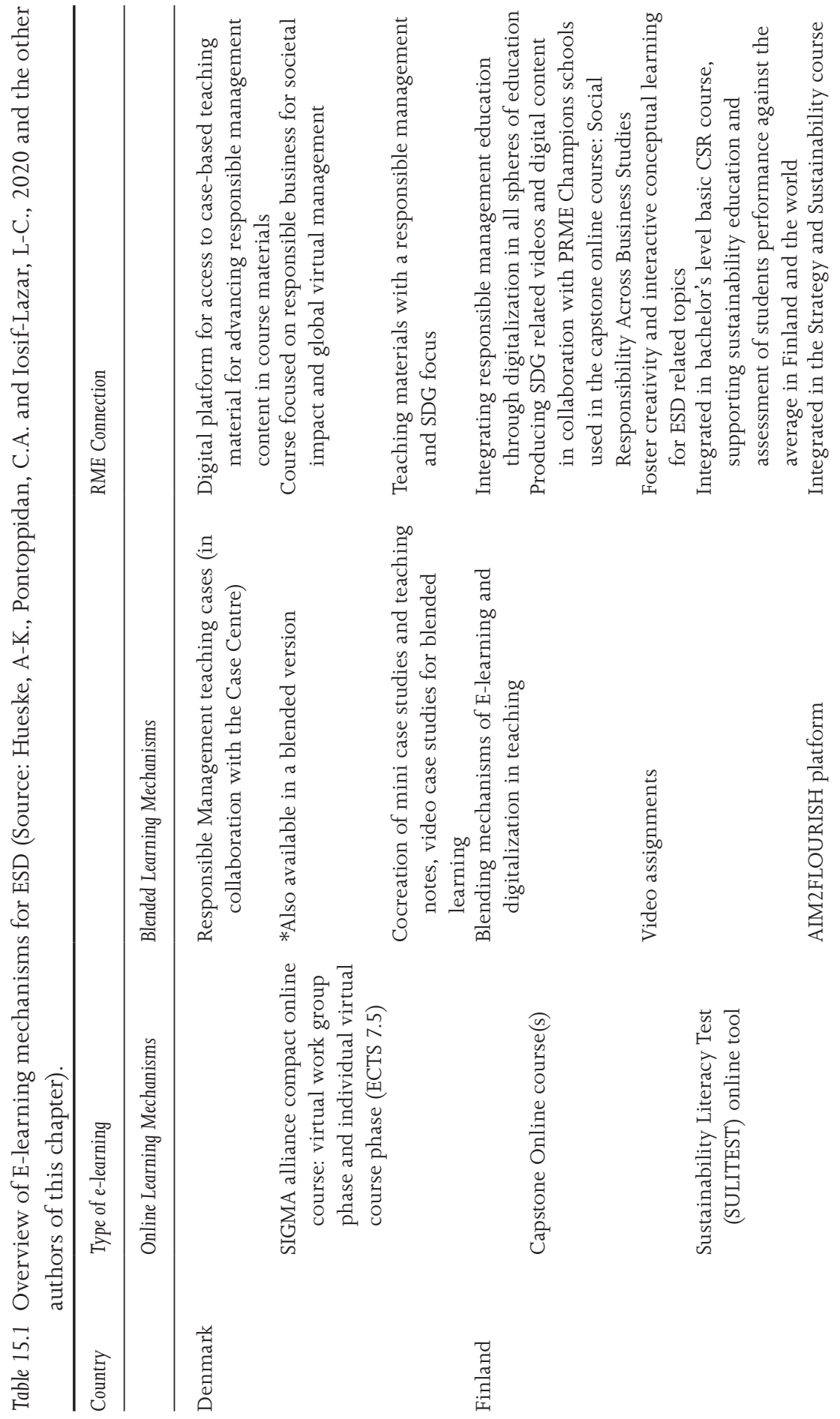




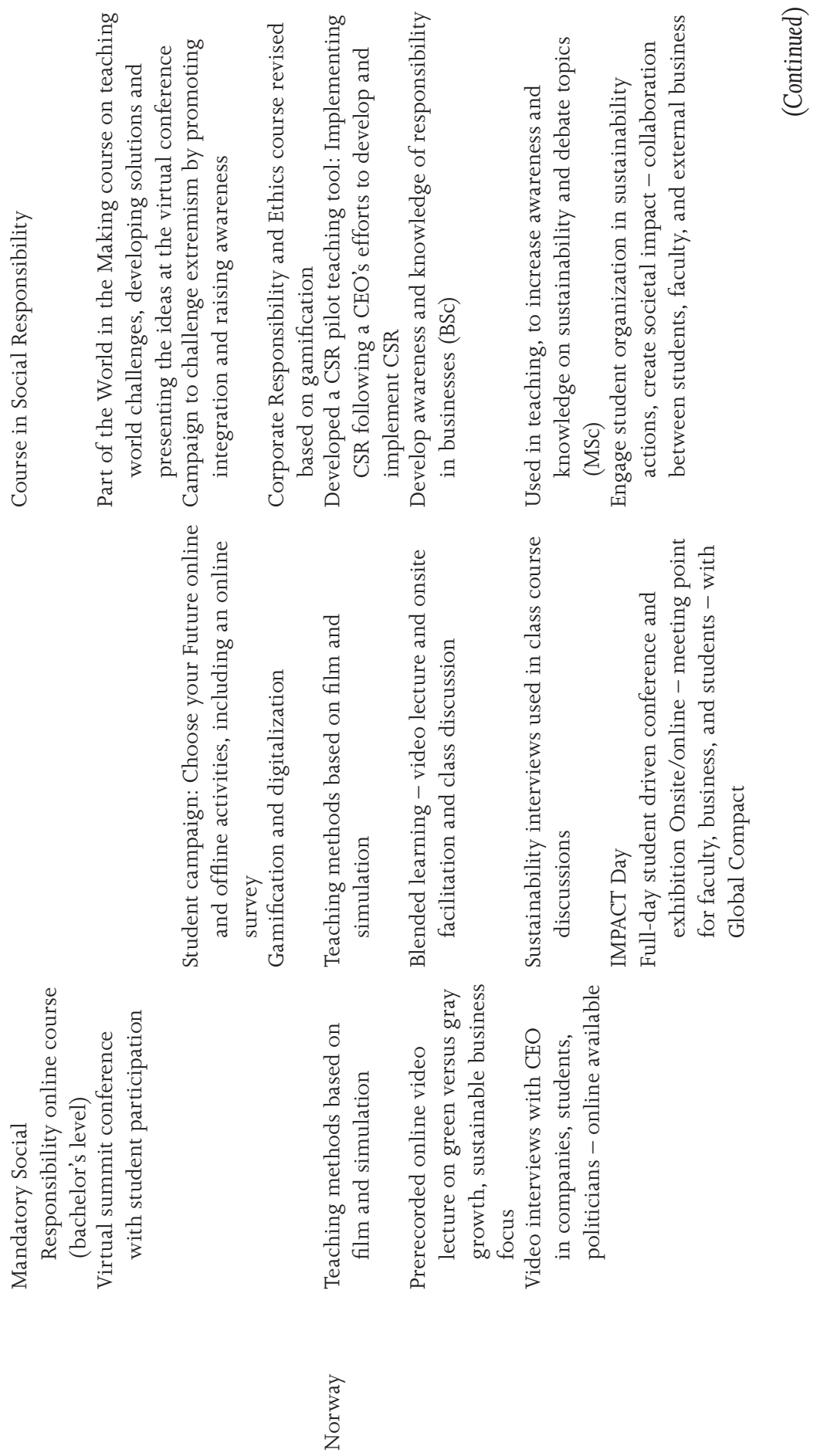




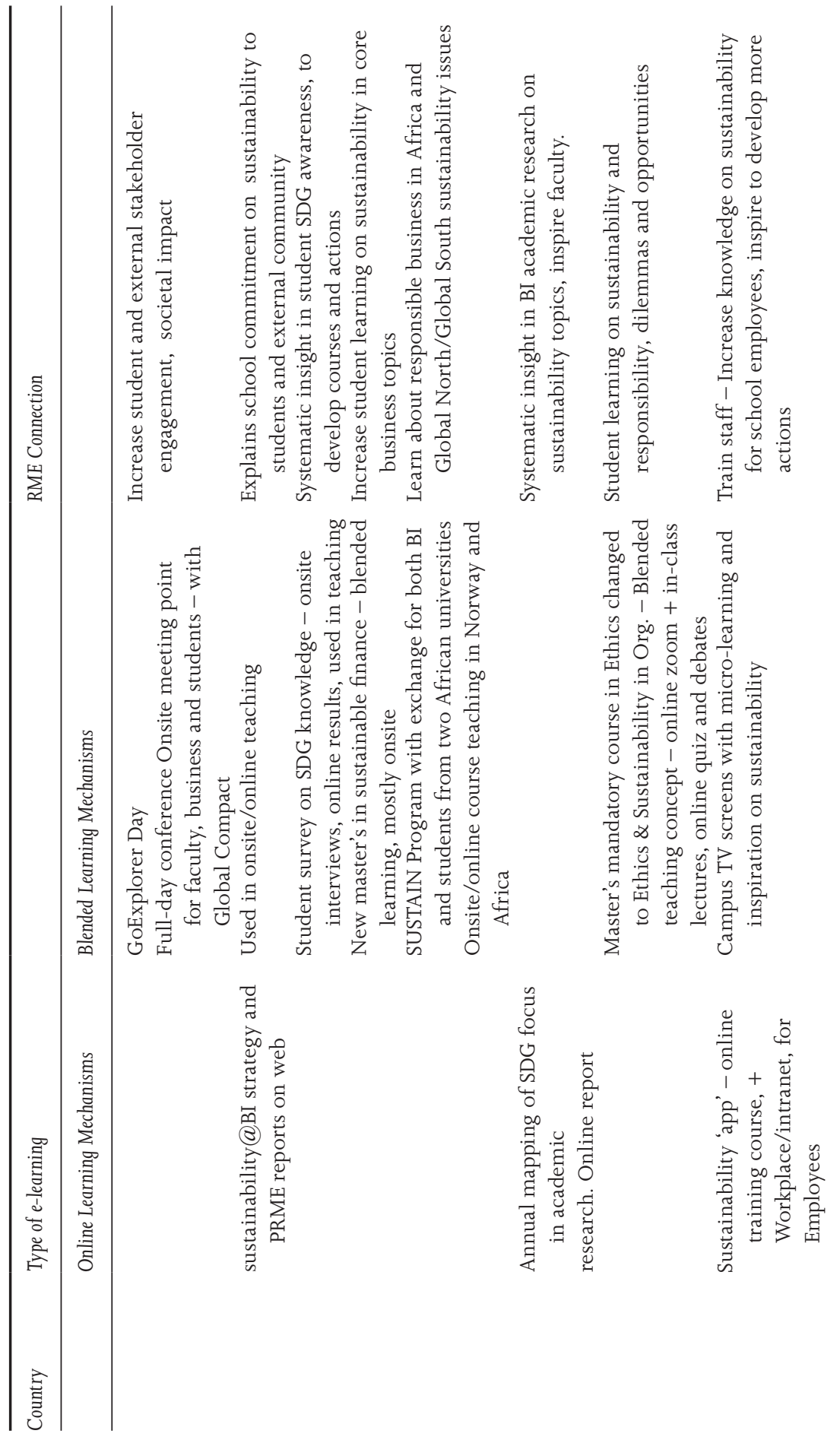




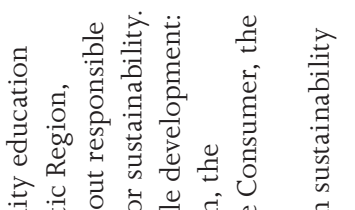

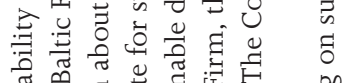
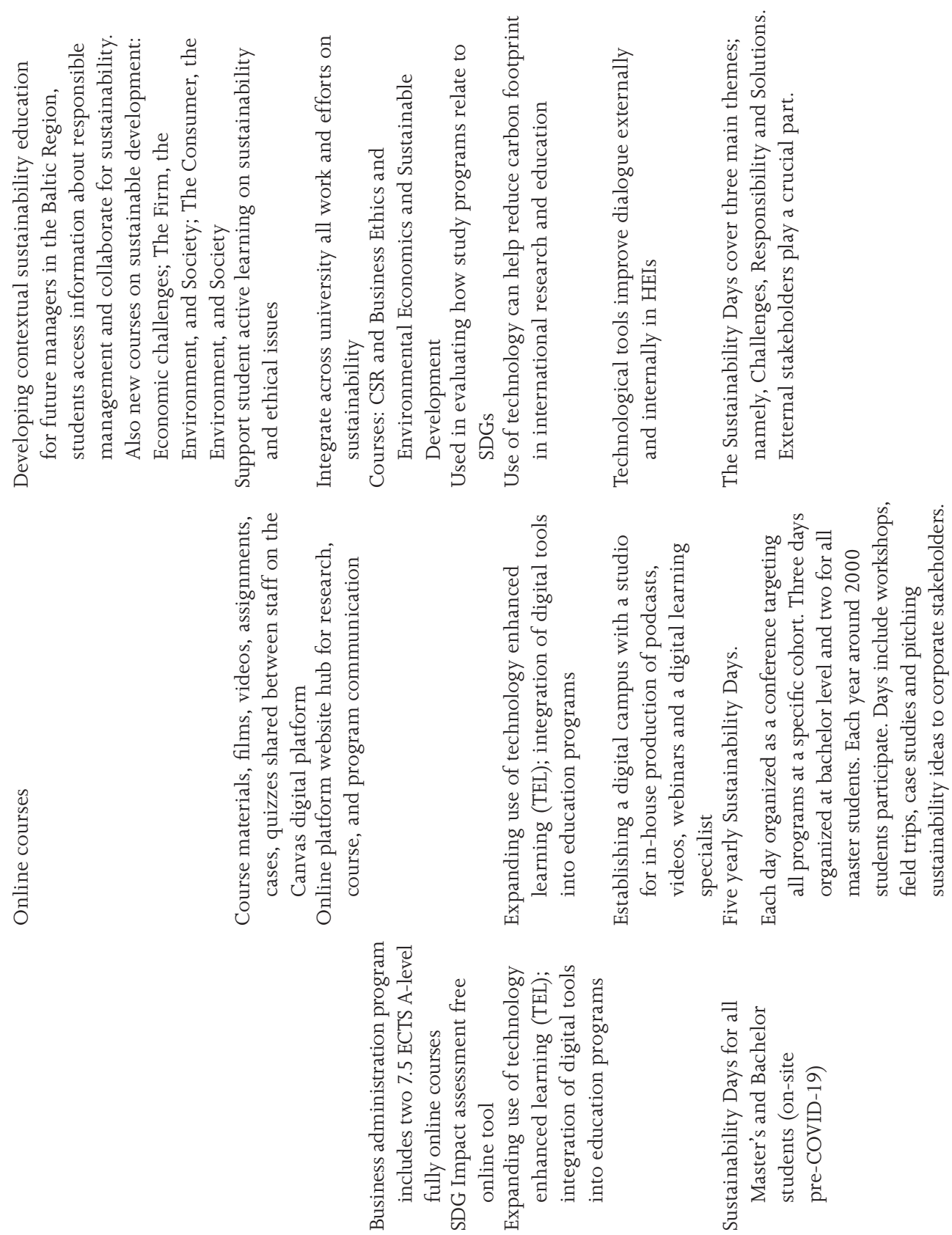
- Jönköping International Business School (JIBS) as part of Jönköping University is mapping all efforts related to education, research, governance, operation management and community engagement on a sustainability dashboard (this is an adapted version of Saint Joseph University, HAUB Business School SDG Dashboard, created by Pr. David Steingard). In 2020, JIBS has decided to give more emphasis to education and see how RME principles can be embedded in all programs, in all courses, to inspire and inform all students in a systematic way. In collaboration with JIBS Associate Dean of Research, surveys and interviews are being conducted with JIBS program directors and JIBS teachers to see how RME principles are being understood and included by faculty members in their courses.

- $\quad$ BI Norway has listed their current courses that have embedded RME principles and is now looking at ways to evaluate all courses and programs.

- At Aalto and Hanken respectively, tagging and labeling both courses and research in relation to the SDGs have been introduced. At Aalto courses are tagged in terms of their relevance and links to particular SDGs, and at Hanken all research output when registered in the research database is tagged, when relevant, to the various SDGs.

\subsection{Recent PRME Nordic Chapter progresses}

2020 Nordic PRME Annual Meeting was preceded by a first time PRME Nordic event: a one-day virtual research symposium on RME was organized by Karlstad Business. The event was largely appreciated and may become an annual tradition in conjunction with the organization of the chapter's annual meeting.

Jönköping International Business School accepted to be Chapter Chair in 2020, for the following two years. Due to common willingness to meet more often and informally, a new tradition was successfully implemented: in addition to the annual meeting, PRME Nordic Chapter has now quarterly morning "breakfasts." These online morning "breakfasts" are an opportunity for available Nordic members to reconnect, share news, and collaborate on common project (codesigning the annual conference, codesigning the book chapter, etc.).

To help share documents in a transparent and efficient manner, we have recently chosen to create an online Microsoft Teams group where all 
documents and meeting notes are shared. Nordic members can modify the documents and share them. We are looking for more ways to inspire each other and to cocreate impactful projects. One way is to help our students collaborate more toward the SDGs.

Although the Chapter is chaired by one school, all members always seek collaboration. Another example of this can be seen in the contribution of the Nordic Chapter to the UN PRME Global Chapter Forum, October 8, 2020 where Jönköping International Business School represented by Guénola Abord-Hugon Nonet offered to facilitate a round table about Covid-19 and Responsible Management Education. Karlstad University and BI Norway supported this initiative and joined the panel.

Through these collaborations, members find inspiration and see the need to have more meetings and also platforms to share their stories and ideas, to help others make similar progress.

\subsection{Critical perspective and potential next steps}

While the Nordic countries are generally well known for advancing thought-leadership and actions in sustainability (Morsing and Strand, 2014; Strand and Freeman, 2015; Strand et al., 2015), contemporary practices do not always meet the standards often envisioned.

A report published by KPMG and FSR - Danish Auditors ${ }^{4}$ shows that only a few large Danish companies report on their own climate impact according to the internationally recognized reporting standard, Greenhouse Gas Protocol. This means that companies' climate data do not provide reliable benchmarks for investors and consumers. More specifically, the review of the companies' climate reporting shows that $88 \%$ of the 2,000 largest Danish companies have completely opted out of reporting on either their climate impact or disclose their $\mathrm{CO}_{2}$ emissions.

Such illustrations of sustainability endeavors not reaching the levels we aim for across the Nordic countries will call for the Nordic PRME community to continue to collectively advance the agenda on responsible management education. Climate change education needs to be at the core of sustainability education in Nordic PRME. It has never been more crucial than today to provide climate education for all, across borders, across school systems, ages and professions. 
The role of education in raising awareness as well as instituting behavioral change for climate change mitigation and adaption is of critical importance (UNESCO 2017, 2020).

PRME Nordic Chapter members see the need to create systemic and systematic change across their schools. They have now achieved the spark of inspiration toward the SDGs and they want to accelerate these developments so that Nordic business schools fully integrate the SDGs in all areas.

This requires dialogue, facilitation, collaboration, and cross-disciplinary and multistakeholder engagement to help address all areas in research, strategy, education, governance, and community engagement and to transform operations so that universities not only learn to talk the walk but also walk the talk.

It is our hope and our common ambition to become inspiring campuses toward the goal of remaining below $1.5^{\circ} \mathrm{C}$ global warming and achieve Agenda 2030 together.

\section{Notes}

1 Availableat:https://www.emerald.com/insight/content/doi/10.1108/IJSHE09-2019-0287/full/html\#refo12

2 E-learning stands for electronic learning and is a method of delivering education via electronic pathways.

3 This table is the collaborative result of work developed by Hueske, A-K., Pontoppidan, C. A., \& losif-Lazar, L-C. (2020) and by the other authors of this chapter.

4 Source: https://home.kpmg/dk/en/home/insights/2020/og/improvementfor-danish-companies--climate-reporting.html

\section{References}

Cunliffe, A.L. (2009) 'The philosopher leader: On relationalism, ethics and reflexivity-A critical perspective to teaching leadership', Management Learning, 40(1), 87-101.

De Geer, H., Borglund, T., and Frostenson, M. (2009) 'Reconciling CSR with the role of the corporation in welfare states: The problematic Swedish example', Journal of Business Ethics, 89(3), 269-283. 
Hodge, P., Wright, S., Barraket, J., Scott, M., Melville, R., and Richardson, S. (2011) 'Revisiting 'how we learn' in academia: Practice-based learning exchanges in three Australian universities', Studies in Higher Education, $36(2), 167-183$.

Hueske, A-K., Pontoppidan, C.A. and Iosif-Lazar, L-C. (2020) E-Learning Mechanisms for Embedding Sustainable Development in Higher Education. Paper presented at 7th RME Research Conference 2020, Switzerland.

KBS (2019) Sharing Information on First Progress Report: 2017-2018, Karlstad Business School PRME office, Karlstad, Sweden.

Morsing, M. and Strand, R. (2014) 'CSR and Beyond. A Nordic Perspective', Corporate Communications: An International Journal. Available at: https:// www.emerald.com/insight/content/doi/10.1108/CCIJ-04-2014-0029/full/ html

Rasche, A. and Gilbert, D.U. (2015) 'Decoupling responsible management education: Why business schools may not walk their talk', Journal of Management Inquiry, 24(3), 239-252.

Roscoe, P. (2020) 'The dark side of responsible management education: An ontological misstep', in The SAGE Handbook of Responsible Management Learning and Education. London: SAGE, 347-362.

Solitander, N., Fougère, M., Sobczak, A., and Herlin, H. (2012) 'We are the champions: Organizational learning and change for responsible management education', Journal of Management Education, 36(3), 337-363.

Strand, R. and Freeman, R.E. (2015) 'Scandinavian cooperative advantage: The theory and practice of stakeholder engagement in Scandinavia', Journal of Business Ethics, 127, 65-85.

Strand, R., Freeman, R.E., and Hockerts, K. (2015) 'Corporate social responsibility and sustainability in Scandinavia: An overview', Journal of Business Ethics, 127(1), 1-15.

UNESCO (2020) Global Education Monitoring Report 2020: Inclusion and Education: All Means All. Paris: UNESCO. Available at: https://en.unesco. org/gem-report/report/2020/inclusion (Accessed g October 2020).

UNESCO (2017) UNESCO at COP23: Climate Change Education. Available at: https://unesdoc.unesco.org/ark:/48223/pfoooo260083 (Accessed 9 October 2020). 